DOI: 10.12731/wsd-2018-5-12-27

УДК 616.718

\title{
ОСТЕОСИНТЕЗ \\ НИЖНЕЧЕЛЮСТНЫХ ПЕРЕЛОМОВ \\ С ИСПОЛЬЗОВАНИЕМ КОНСТРУКЦИЙ ИЗ НИКЕЛИДА ТИТАНА
}

\author{
Радкевич А.А., Гюнтер В.Э., Синюк И.В., \\ Левенец А.А., Стынке Г.М., Мамедов Р.Х., Подгорный В.Ю., \\ Гантимуров А.А., Журавлева Т.Б.
}

Цель. Разработка новой медицинской технологии хирургического лечения больных с переломами нижней челюсти с использованием материалов с памятью формыл.

Материалы и методы. С использованием фиксирующих конструкций из никелида титана с памятью формы, разработанных в НИИ медицинских материалов и имплантатов с памятью формы, выполнено оперативное лечение более 2000 больных, лии обоего пола, в возрасте от 13 до 80 лет, с переломами нижней челюсти различного характера и локализации из внутриротового или внеротового доступов без иммобилизации нижней челюсти и комбинации с другими способами остеосинтеза.

Результаты. Применение фиксируюших конструкиий с термомеханической памятью в хирургическом лечении различных типов переломов нижней челюсти позволило получить удовлетворительные результать y 95,5\% больных. В остальных 4,5\% случаях возникли осложнения в виде нагноения костной раны, травматического остеомиелита, что связано с поздними обращениями и/или угнетением репаративной функиии, замедленная консолидация, в основном у лии старшего и пожилого возраста, в результате трофических нарушений.

Заключение. Благодаря биосовместимости никелида титана с тканями организма остеосинтез переломов нижней челюсти с использованием скоб из данного материала позволяет свести до минимума все виды осложнений, присущие этому типу вмешательств.

Ключевые слова: никелид титана; переломы нижней челюсти; остеосинтез. 


\section{OSTEOSYNTHESIS OF MANDIBULAR FRACTURES USING CONSTRUCTIONS MADE OF TITANIUM NICKELIDE}

Radkevich A.A., Gyunter V.E., Sinuk I.V., Levenets A.A., Stinca G.M., Mamedov R.H., Podgorny V.Yu., Gantimurov A.A., Zhuravleva T.B.

Purpose. Development of new medical technology of surgical treatment of patients with mandibular fractures using materials with shape memory.

Materials and methods. With the use of fixing structures made of titanium nickelide with shape memory, developed in the research Institute of medical materials and implants with shape memory, surgical treatment of more than 2,000 patients, both sexes, aged 13 to 80 years, with fractures of the lower jaw of various nature and localization of intraoral or extraoral accesses without immobilization of the lower jaw and combination with other methods of osteosynthesis.

Results. The use of fixing structures with thermomechanical memory in the surgical treatment of various types of mandibular fractures allowed to obtain satisfactory results in $95.5 \%$ of patients. In the remaining $4.5 \%$ of cases there were complications in the form of suppuration of bone wounds, traumatic osteomyelitis, which is associated with late treatment and/or inhibition of reparative function, delayed consolidation, mainly in older and elderly people, as a result of trophic disorders.

Conclusion. Due to the biocompatibility of titanium nickelide with tissues of the body, osteosynthesis of mandibular fractures using staples from this material allows to minimize all kinds of complications inherent in this type of intervention.

Keywords: titanium nickelide; mandibular fractures; osteosynthesis.

\section{Введение}

Среди повреждений лицевого черепа переломы нижней челюсти занимают ведущее место и составляют $60-70 \%[1,4,8,14]$. Таким больным в случаях смещения отломков показан остеосинтез. Данный вид хирургического лечения следует предпочесть ортопедическим методам фиксации отломков, в силу предотвращения негативные моментов, связанных с их применением, таких как травматический пародонтит, дисфункциональные явления со стороны височно-нижнечелюстных су- 
ставов, замедленная консолидация и др., в том числе и большие сроки нетрудоспособности.

Для успешного выполнения оперативных вмешательств, связанных с остеосинтезом, необходимо соблюдение следующих условий: обеспечение надежной фиксации костных фрагментов, так как нестабильный синтез удлиняет сроки реабилитации, ведет к несращениям, формированию ложных суставов, нагноению костных ран и вытекающим их этого осложнениям, неправильной консолидации, дисфункции височно-нижнечелюстных суставов, деформации лица и зубных рядов и др.; выбор конструкций, не подвергающихся коррозии в организме, что не будет создавать условий для необходимости их последующего удаления, не нарушающих контурности лица, не требующих значительных травматических тканевых повреждений и временных затрат в процессе их применения.

В настоящее время существует множество методов остеосинтеза, применяемых в практической челюстно-лицевой хирургии, такие как синтез швом кости проволокой, спицами Киршнера, различные варианты интрамедуллярного синтеза, применение накостных рамок с винтами, внеочаговых аппаратов и др. $[3,9,10]$. Все они или низкоэффективны, или довольно травматичны, последние содержат громоздкие конструкции, что помимо высокой травматичности причиняет значительные неудобства пациентам. Кроме того, за счет применения не биосовместимых металлических конструкций (нержавеющих сталей, титана, тантала, кобальта-хромо-молибденовые, кобальта-хромо-ванадия-никелевых, титана-алюминиево-ванадиевых сплавов и др.) возможна только жесткая фиксация, возникают отрицательные моменты, связанные с проблемами биосовместимости. Большая часть отечественных и зарубежных хирургов в целях оперативного закрепления костных отломков используют накостные титановые перфорированные пластины с винтовыми креплениями или синтез титановыми винтами [2, 7, 10, 12-15]. Методика их применения травматична, так как требует нанесения большого количества фрезевых отверстий и, в соответствие с этим, скелетирования отломков или фрагментов, использования саморезов, головки которых при вкручивании и выкручивании часто развальцовываются, связана с большими временными затратами. Титановые минипластины нередко прорезываются в полость рта, саморезы мигрируют в толщу окружающих тканей, зачастую уже в ближайшем послеоперационном периоде рентгенологически наблюдаются явления деструкции костной ткани в зоне винтовой фиксации, а у лиц с порозными костями эффектитвность 
данного вида остеосинтеза становится неудовлетворительной. Кроме того, титановые имплантаты в тканях организма подвергаются коррозии за счет повреждения оксидного слоя благодаря разнице в поведении биологических тканей и титана при функциональной (знакопеременной более $0,2 \%$ ) деформации, что ведет к химическому взаимодействию титана с кислородом тканевой жидкости и высвобождению ионов титана в окружающие ткани с последующим образованием оксида титана. В этой связи данные ткани приобретают металлическую окраску, что многие специалисты называют «металозом». Данный термин не отражает сущность описанных явлений и не является научным. Клинически указанная ситуация характеризуется интоксикацией организма, сопровождающейся слабостью, повышенной утомляемостью, нарушением сна, хроническими бронхитами, часто с явлениями бронхоспазма, развитием дыхательной недостаточности, гипоксией миокарда. Локально наблюдаются воспалительные и деструктивные изменения реципиентных тканей, требующие удаления имплантируемых конструкций, иссечения измененных тканевых структур и других вмешательств, приводящих к тканевым дефектам. Не спасает от вышеописанных явлений нанесение на титан и нержавеющие стали нитрида титана и других покрытий, так как за их счет не улучшаются эластические свойства данных материалов. Большинство специалистов в нашей стране и за рубежом, считая титан исключительно биологически инертным, склонны к тому, что из него изготовленные минипластины и винты не требуют последующего удаления из организма. Однако французский ученый М. Champi, являясь одним из основоположников этого метода, еще в 1993 году на 2-м Средиземноморском конгрессе показал использованные в практической челюстно-лицевой хирургии титановые минипластины с явлениями коррозии и однозначно высказал свою позицию за их удаление даже при отсутствии клинических проявлений несовместимости [11]. Признаки коррозии удаленных из тканей титановых минипластин обнаружили и М.Б. Швырков с соавт. (1999) [10]. В своих публикациях вышеуказанные авторы констатируют отсутствие коррозии используемых винтов, подчеркивая факт изготовления последних из титана той же марки, из чего можно сделать вывод о лучшей адаптации винтовых конструкции к функционирующим биологическим тканям, в сравнении с пластинчатыми, с чем нельзя согласиться. Опираясь на собственный клинический опыт и знания физики, мы можем утверждать, что отсутствие коррозии титановых винтов, находящихся в костных тканях, объясняется их меньшими размерами, и 
отсутствие биосовместимости сопровождается деструкцией реципиентной костной ткани, в силу закономерностей поведения тканей организма по пути наименьшего сопротивления. При отсутствии деструктивных явлений со стороны костных структур деструкции винтов не наблюдается потому, что в этих случаях постепенная пластическая деформация и разрушение пластинчатых элементов конструкции ведет к постепенному ослаблению напряжений в толще тканей, имеющих с винтовыми соединениями непосредственный контакт.

Цель работы: Повышение эффективности хирургического лечения больных с переломами нижней челюсти путем разработки новых медицинских технологий с использованием материалов с памятью формы.

\section{Материалы и методы}

В НИИ медицинских материалов и имплантатов с памятью формы (г. Томск) разработаны фиксирующие конструкции для синтеза костных структур лицевого черепа, изготовленные из сплава марки ТН-10 на основе никелида титана, обладающих эффектом памяти формы (рис. 1). Данные конструкции удовлетворяют самым строгим медико-техническим требованиям, предъявляемым к имплантационным материалам, и характеризуются оптимальным сочетанием удельного веса, прочности и пластичности, износо- и циклостойкости, коррозионной стойкости и значительным сопротивлением усталости. Благодаря биохимической и биомеханической совместимости никелида титана с тканями организма, что обеспечивается не только его химической инертностью к биологическим жидкостям, но и способностью деформироваться и восстанавливать исходную форму в условиях нагрузки и разгрузки (обратимые деформационные изменения) в соответствие с законом запаздывания, т.е. гистерезисного поведения биологических тканей и систем живой природы, имплантаты на его основе не отторгаются, а гармонично взаимодействуют с различными тканями и органами в процессе их функционирования $[5,6]$. Конструкции изготовлены из проволоки диаметром 0,8-2 мм состоят из ножек, служащих для погружения в толщу кости, и соединяющей их средней части, имеющей изгибы или без таковых. Эффект памяти формы данных конструкций во время остеосинтеза привлекает внимание специалистов тем, что данная конструкция при определенных условиях (охлаждении) может изменять ранее заданную форму и восстанавливать ее при нагревании до температуры тела пациента, что позволяет создавать условия по форме, удобные для введения в ткани организма. 


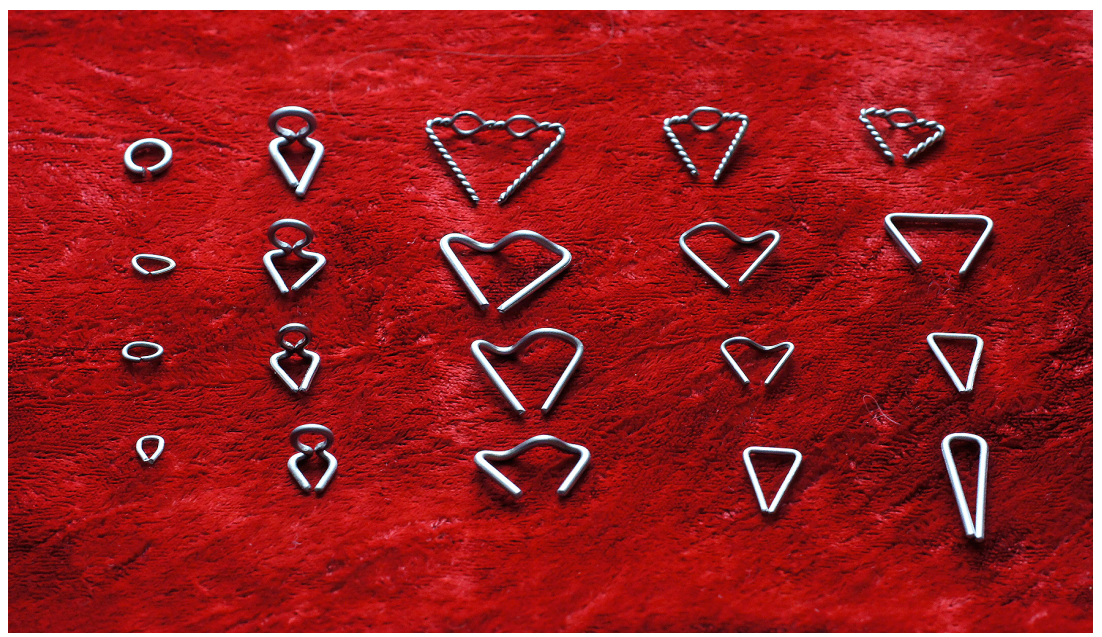

Pис. 1. Набор фиксирующих конструкций из никелида титана марки ТН-10 для челюстно-лицевой хирургии

У больных с переломами тела нижней челюсти в пределах зубного ряда остеосинтез следует выполнять из внутриротового доступа. Данное обстоятельство связано как с эстетическими моментами, так и тем, что указанные повреждения, как правило, являются открытыми (т.е. сообщающимися с ротовой полостью). Внутриротовой доступ возможно использовать и во многих случаях переломов угла и ветви путем дополнительного рассечения тканей ретромолярной области и в проекции переднего края ветви челюсти.

Методика остеосинтеза. Выполняют дугообразный разрез слизистой оболочки и надкостницы выше переходной складки или выкраивают трапециевидный слизисто-надкостничный лоскут в проекции перелома отступя в дистальном и медиальном направлении на длину, соответствующую ширине коронковой части 2-х или 2,5 соседних зубов (при их отсутствии на величину, соразмерную им). В зависимости от показаний зубы, корни которых находятся в щели перелома, удаляют. Скелетируют наружную компактную поверхность по обе стороны от перелома вплоть до основания нижней челюсти. После репозиции, отступя от края отломков на $0,5-$ 1,5 см, наносят сквозные фрезевые отверстия перпендикулярно плоскости повреждения по одному, два или в большем количестве с каждой стороны (в зависимости от клинических особенностей) диаметром на 0,2-0,3 мм 
больше диаметра ножки фиксирующих устройств с учетом топографии корней зубов, нижнечелюстного канала и других имеющих значение анатомических структур. Скобу из никелида титана, имеющую линейный размер средней трети меньший на 2-5 мм, чем расстояние между фрезевыми отверстиями, обрабатывают в хладагенте для охлаждения до $+3^{\circ} \mathrm{C}$ или ниже, после чего ей придают оптимальную форму и погружают ножки конструкции полностью внутрь нанесенных ранее фрезевых отверстий. После контактного нагрева до $+35^{\circ} \mathrm{C}$ фиксирующий элемент за счет эффекта памяти формы восстанавливает исходную форму, тем самым осуществляя костную фиксацию. В случаях нарушающих конфигурацию нижнечелюстной кости за счет контурности фиксирующих элементов в проекции средней части конструкции следует создавать фрезевой канал, способствующий ее погружению в толщу компактного слоя. Добившись эффективного остеосинтеза, рану дренируют и ушивают.

Синтез средней и верхней части ветви челюсти, включая мыщелковый отросток, возможно проводить из зачелюстного или предушного доступа, наружный доступ также следует использовать в силу низкой эффективности внутриротового и при других локализациях перелома. Количество и вид фиксирующих конструкций следует выбирать в зависимости от характера повреждения. При неэффективности одного фиксирующего элемента, остеосинтез необходимо дополнять второй и, по мере необходимости, последующими конструкциями, убедившись в достижении удовлетворительного результата. Мы не разделяем мнение специалистов, утверждающих, что существуют такие переломы, при которых применение конструкций с памятью формы невозможно и в ряде клинических ситуаций следует от них вовсе отказаться, заменив на жесткую фиксацию пластинами с винтами, или их использовать в комбинации с указанными пластинами и/или швом кости проволокой, а также другими известными методами.

С использованием фиксирующих конструкций из никелида титана с эффектом памяти формы выполнено оперативное лечение более 2000 больных, лиц обоего пола, в возрасте от 13 до 80 лет, с переломами нижней челюсти различного характера и локализации (табл. 1).

При обследовании больных использовали основные клинические и рентгенологические методы исследования. Анатомические и функциональные результаты лечения оценивали на основании наблюдений за больными в ближайшем послеоперационном периоде и в отдаленные сроки в течение последующих 1-5-ти лет после оперативного вмешательства. 
Таблицча 1.

Количественная характеристика оперированных больных с переломами нижней челюсти с использованием конструкций из никелида титана

\begin{tabular}{|l|c|c|c|c|}
\hline \multicolumn{1}{|c|}{ Нозологическая форма } & Возраст, & \multicolumn{2}{|c|}{ Пол } & Кол-во \\
\cline { 3 - 5 } & лет & мужской & женский & больных \\
\hline Перелом тела & $16-73$ & 117 & 66 & 183 \\
\hline Перелом угла & $15-78$ & 412 & 128 & 540 \\
\hline Перелом ветви & $27-55$ & 82 & 25 & 107 \\
\hline Перелом мыщелкового отростка & $15-79$ & 229 & 47 & 276 \\
\hline Двусторонний перелом тела & $16-80$ & 51 & 22 & 73 \\
\hline Двусторонний перелом углов & $16-75$ & 90 & 41 & 131 \\
\hline Двусторонний перелом ветвей & $17-69$ & 20 & 9 & 29 \\
\hline $\begin{array}{l}\text { Двусторонний перелом мыщелковых } \\
\text { отростков }\end{array}$ & $14-75$ & 53 & 43 & 96 \\
\hline Двусторонний перелом тела и угла & $14-77$ & 62 & 18 & 80 \\
\hline Двусторонний перелом тела и ветви & $18-62$ & 29 & 8 & 37 \\
\hline $\begin{array}{l}\text { Двусторонний перелом тела и } \\
\text { мыщелкового отростка }\end{array}$ & $13-77$ & 106 & 27 & 133 \\
\hline Двусторонний перелом угла и ветви & $17-71$ & 24 & 12 & 36 \\
\hline $\begin{array}{l}\text { Двусторонний перелом угла и } \\
\text { мыщелкового отростка }\end{array}$ & $18-75$ & 42 & 30 & 72 \\
\hline $\begin{array}{l}\text { Двусторонний перелом ветви и } \\
\text { мыщелкового отростка }\end{array}$ & $27-63$ & 29 & 6 & 35 \\
\hline Тройной перелом тела и углов & $33-62$ & 10 & 2 & 12 \\
\hline Тройной перелом тела, угла и ветви & $28-48$ & 15 & 2 & 17 \\
\hline $\begin{array}{l}\text { Тройной перелом тела, угла и } \\
\text { мыщелкового отростка }\end{array}$ & $30-54$ & 31 & 11 & 42 \\
\hline $\begin{array}{l}\text { Тройной перелом тела и мыщелковых } \\
\text { отростков }\end{array}$ & $13-50$ & 55 & 21 & 76 \\
\hline Множественный перелом & $26-48$ & 19 & 6 & 25 \\
\hline Всего & $13-80$ & 1476 & 517 & 2000 \\
\hline
\end{tabular}

*в целях уменьшения громоздкости таблицы двойные переломы включены в графы

\section{Результаты}

Применение фиксирующих конструкций из никелида титана с памятью формы в хирургическом лечении различных типов переломов нижней челюсти позволило получить удовлетворительные результаты у 1910 (95,5\%) больных, без признаков каких-либо осложнений. При неосложненном течении в первые дни после вмешательства во всех случаях выявлялась отечность мягких тканей, в том числе гиперемия слизистой оболочки в зоне операции у 
лиц после использования внутриротового доступа, которые в скором времени регрессировали, начиная со 2-3 суток, и, как правило, полностью купировались в течение 6-10 дней. Через 2-3 недели, субъективно, пациенты чувствовали себя вполне здоровыми. Спустя 3-4 недели больные принимали жесткую пищу, клинически определялись признаки консолидации перелома, о чем свидетельствовало отсутствие болевых ощущений в зоне вмешательства, патологической подвижности отломков, удовлетворительный объем открывания рта. Нарушений соотношения зубных рядов, связанных с остеосинтезом, не наблюдали. В отдаленные сроки пациенты жалоб не предъявляли, функциональных нарушений со стороны зубочелюстного аппарата, причиной которых могли бы служить выполненные оперативные вмешательства, не отмечено.

Рентгенологически у больных этой группы в зоне бывших дефектов констатировано удовлетворительное стояние отломков, патологических щелевых дефектов между последними не выявлялось. Начиная с 3-х недельного срока, постепенно нарушалась четкость теней линий переломов, которая к 1,5-2-м месяцам определялась в виде повышенной интенсивности затемнения, что свидетельствовало об образованной костной мозоли. Миграции фиксирующих конструкций не отмечалось. В более поздний период (660 мес.) деструктивных изменений в области контактирования фиксаторов с костными тканями и таких явлений как убыль костной ткани, за исключением альвеолярной части в зонах удаленных зубов, не наблюдали.

Из 90 больных с осложненным течением послеоперационного периода в 43 случаях возникло нагноение костной раны, в 20 - осложнения в виде травматического остеомиелита, что связано с поздними обращениями и/ или угнетением репаративной функции, у 27 пациентов наблюдалась замедленная консолидация, в основном у лиц старшего и пожилого возраста, в результате трофических нарушений. Данные ситуации потребовали соответствующей терапии и, у больных с травматическим остеомиелитом, повторного хирургического вмешательства.

В качестве иллюстрации приводим наблюдение. Больной B., 46 лет, поступил в клинику с диагнозом двусторонний перелом нижней челюсти (угла справа, тела слева). Из анамнеза: травму получил в результате автодорожной травмы, доставлен в ЦРБ по месту жительства, где были наложены шины Тигеритедта, на следующий день направлен на стационарное лечение (рис. 2а-с). После госпитализации удалены назубные шины, выполнен двусторонний остеосинтез нижней челюсти согласно предлагаемой технологии. Послеоперационное течение без особенностей. Рентгенографическая картина через 3 мес. представлена на рис. $2 \mathrm{~d}-\mathrm{g}$. 


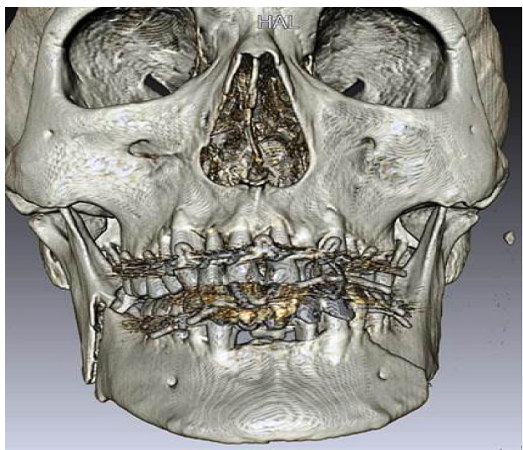

$2 a$

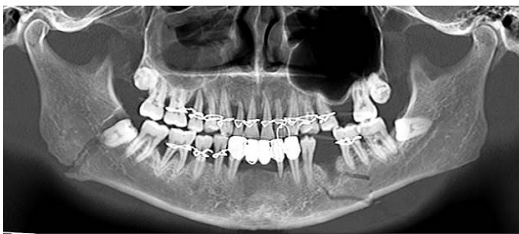

$2 c$

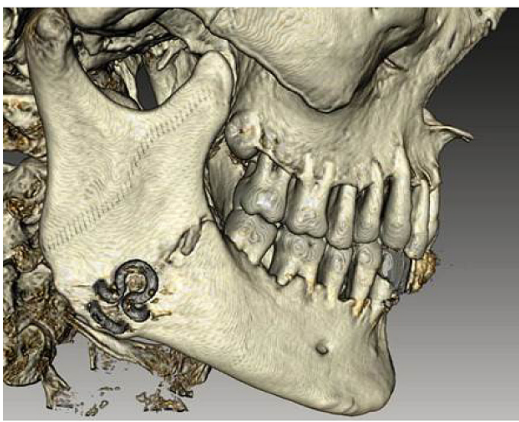

$2 e$

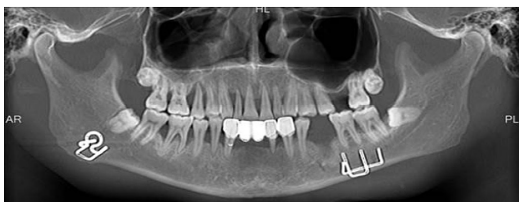

$2 g$

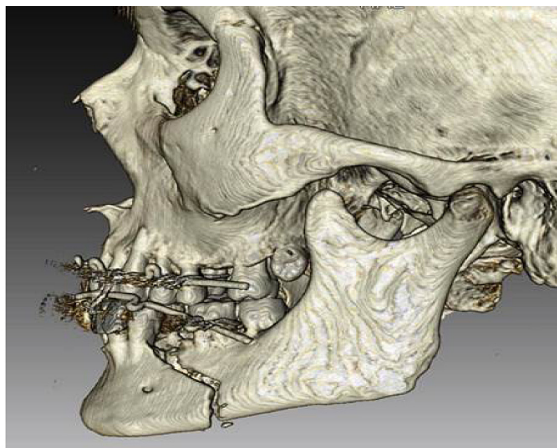

$2 b$
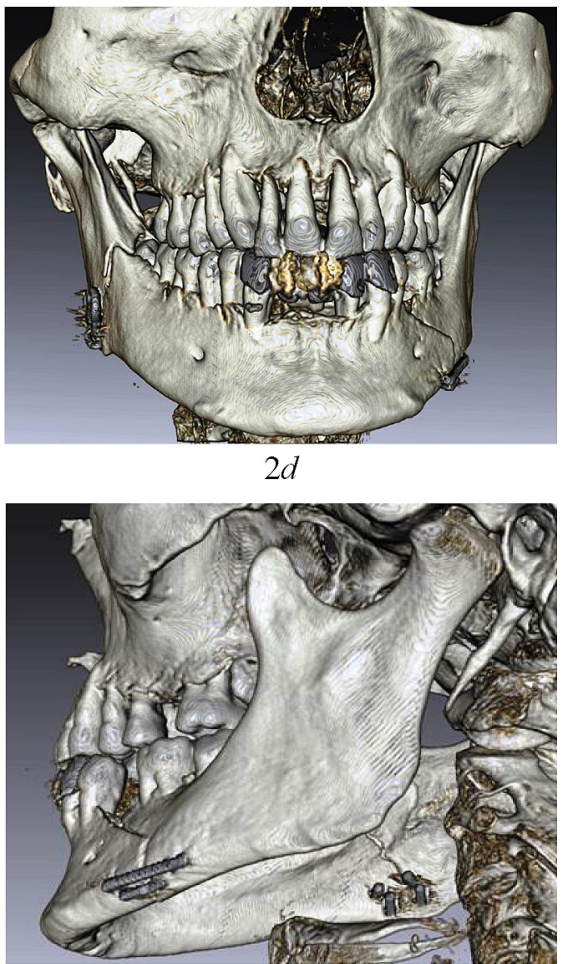

$2 f$

Рис. 2. Рентгенографическая картина больного В.: $a-c$ - до-; $d$-g - через 3 мес. после остеосинтеза 


\section{Заключение}

Таким образом, наблюдения показали, что остеосинтез переломов нижней челюсти с использованием в качестве фиксирующих конструкций скоб из никелида титана с памятью формы позволяет свести до минимума все виды осложнений, присущие этому типу вмешательств. Данный остеосинтез прост в применении, малотравматичен, обеспечивает стабильную эластическую фиксацию любых вариантов переломов, не требует значительных временных затрат, иммобилизации нижней челюсти, дает возможность осуществления беспрепятственной ранней функциональной нагрузки, способствующей быстрой консолидации отломков. Благодаря биосовместимости никелида титана с тканями организма, устройства, используемые для остеосинтеза, не оказывают отрицательного воздействия на костные и мягкие ткани, не требуют повторных хирургических вмешательств по их удалению.

\section{Список литературы}

1. Амро А. Особенности клинической картины переломов нижней челюсти в различные возрастные периоды / А. Амро, В.В. Самсонов, Г.А. Гребнев и др. // Вестн. Рос. воен.-мед. академии. 2012. №4 (40). С. 49-51.

2. Выбор метода остеосинтеза при высоких переломах мыщелкового отростка нижней челюсти / Д.Ш. Девдариани, А.В. Куликов, А.С. Багненко и др. // Вестник Северо-Западного государственного медицинского университета им. И.И. Мечникова. Т.9, № 1. 2017. С. 54-58.

3. Использование костного шва при косых переломах нижней челюсти / Ю.В. Ефимов, Д.В. Стоматов, С.В. Поройский и др. // Волгоградский научно-медицинский журнал. 2015. № 1.С. 53-55.

4. Козлов П.Ю. Ретроспективный анализ переломов нижней челюсти в области мыщелкового отростка нижней челюсти по данным отделения челюстно-лицевой хирургии ГНОКБ // Материалы VII Российской (итоговой) научно-практической конференции с международным участием студентов и молодых ученых «Авиценна-2016»: в 2 т. Новосибирск: Сибмедиздат НГМУ, 2016. Т.2. С. 266-268.

5. Медицинские материалы и имплантаты с памятью формы. Имплантаты с памятью формы в челюстно-лицевой хирургии. Т.4 / П.Г. Сысолятин, В.Э. Гюнтер, С.П. Сысолятин и др. Томск: Изд-во МИЦ, 2012. 384 с.

6. Медицинские материалы и имплантаты с памятью формы. Медицинские материалы с памятью формы. Т.1 / В.Э. Гюнтер, В.Н. Ходоренко, Т.Л. Чекалкин и др. Томск: Изд-во МИЦ, 2011. 534 с. 
7. Опыт и перспективы хирургического лечения высоких переломов мыщелковых отростков нижней челюсти со смещением отломков / Ю.А. Медведев, Ю.Н. Сергеев, Н.С. Бедирханлы и др. // Здоровье и образование в XXI веке. 2009. № 1. С. 64-67.

8. Патоморфоз и современная эволюция профессиональных и производственно обусловленных заболеваний / И.О. Маринкин, Е.Л. Потеряева, Л.А. Шпагина и др. // Медицина труда и промышленная экология. 2010. № 8. C. $1-6$.

9. Трубина А.В. Анатомическое обоснование выбора метода остеосинтеза спицей при переломах мыщелкового отростка нижней челюсти / А.В. Трубина, В.В. Трубин, Л.М. Меркулова // Здоровье и образование в XXI веке. 2016. № 8. C. 30-32.

10. Швырков М.Б. Неогнестрельные переломы челюстей / М.Б. Швырков, В.В. Афанасьев, В.С. Стародубцев. М.: Медицина, 1999. 336 с.

11. Champy M. Is it necessary to remove the osteosynthesis plates in maxillofacial surgery? / M. Champy // 2nd Mediterranean Cjngress of Oral and Maxillofacial Surgery. Greece, 1993. P. 12.

12. Endoscope-Assisted Transoral Fixation of Mandibular Condyle Fractures: Submandibular Versus Transoral Endoscopic Approach / N-H. Hwang, Y-H. Lee, H-J. You et al. // J. Craniofac. Surg. 2016. V. 27, pp. 1170-1174.

13. Mandibular Condylar Fractures in Children: Morphofunctional Results After Treatment With External Fixation / P. Cascone, M.M. Marcozzi, V. Ramieri et al. // J. Craniofac. Surg. 2017. V. 00, № 00, pp. 1-4. DOI: http://dx.doi.org/10.1097/ SCS.0000000000003914

14. Maxillofacial fracture epidemiology and treatment plans in the Northeast of Iran: A retrospective study / S. Samieirad, M-R. Aboutorabzade, E. Tohidi et al. // Med. Oral. Patol. Oral. Cir. Bucal. 2017. V. 22, № 1, pp. 616-624.

15. Use of Resorbable Fixation System in Pediatric Facial Fractures / K. Frankie, B.A. Wong, A. Saleigh et al. // J. Craniofac. Surg. 2017. V. 28, № 3, pp. 635-637.

\section{References}

1. Amro A., Samsonov V.V., Grebnev G.A. et al. Vestn. Ros. voen.-med. akademii. 2012. №4 (40), pp. 49-51.

2. Devdariani D.Sh., Kulikov A.V., Bagnenko A.S. et al. Vestnik Severo-Zapadnogo gosudarstvennogo meditsinskogo universiteta im. I.I. Mechnikova. V.9, № 1. 2017, pp. 54-58.

3. Efimov Yu.V., Stomatov D.V., Poroyskiy S.V. et al. Volgogradskiy nauchnomeditsinskiy zhurnal. 2015. № 1, pp. 53-55. 
4. Kozlov P.Yu. Materialy VII Rossiyskoy (itogovoy) nauchno-prakticheskoy konferentsii s mezhdunarodnym uchastiem studentov i molodykh uchenykh «Avitsenna-2016» [Proceedings of the VII Russian (final) scientific-practical conference with international participation of students and young scientists “Avicenna-2016"]. Novosibirsk: Sibmedizdat NGMU, 2016. V.2, pp. 266-268.

5. Sysolyatin P.G., Gyunter V.E., Sysolyatin S.P. et al. Meditsinskie materialy $i$ implantaty s pamyat'yu formy. Implantaty s pamyat'yu formy $v$ chelyustno-litsevoy khirurgii [Medical materials and implants with shape memory. Implants with shape memory in maxillofacial surgery]. V.4.Tomsk: Izd-vo MITs, 2012. $384 \mathrm{p}$.

6. Gyunter V.E., Khodorenko V.N., Chekalkin T.L. et al. Meditsinskie materialy $i$ implantaty s pamyat'yu formy. Meditsinskie materialy s pamyat'yu formy [Medical materials and implants with shape memory. Medical materials with shape memory]. V.1. Tomsk: Izd-vo MITs, 2011. 534 p.

7. Medvedev Yu.A., Sergeev Yu.N., Bedirkhanly N.S. et al. Zdorov'e i obrazovanie v XXI veke. 2009. № 1, pp. 64-67.

8. Marinkin I.O., Poteryaeva E.L., Shpagina L.A. et al. Meditsina truda i promyshlennaya ekologiya. 2010. № 8, pp. 1-6.

9. Trubina A.V., Trubin V.V., Merkulova L.M. Zdorov'e i obrazovanie v XXI veke. 2016. № 8, pp. 30-32.

10. Shvyrkov M.B., Afanas'ev V.V., Starodubtsev V.S. Neognestrel'nye perelomy chelyustey [Non-fire fractures of the jaws]. M.: Meditsina, 1999. $336 \mathrm{p}$.

11. Champy M. Is it necessary to remove the osteosynthesis plates in maxillofacial surgery? 2nd Mediterranean Cjngress of Oral and Maxillofacial Surgery. Greece, 1993. P. 12.

12. N-H. Hwang, Y-H. Lee, H-J. You et al. Endoscope-Assisted Transoral Fixation of Mandibular Condyle Fractures: Submandibular Versus Transoral Endoscopic Approach. J. Craniofac. Surg. 2016. V. 27, pp. 1170-1174.

13. P. Cascone, M.M. Marcozzi, V. Ramieri et al. Mandibular Condylar Fractures in Children: Morphofunctional Results After Treatment With External Fixation. J. Craniofac. Surg. 2017. V. 00, № 00, pp. 1-4. DOI: http://dx.doi.org/10.1097/ SCS.0000000000003914

14. S. Samieirad, M-R. Aboutorabzade, E. Tohidi et al. Maxillofacial fracture epidemiology and treatment plans in the Northeast of Iran: A retrospective study. Med. Oral. Patol. Oral. Cir. Bucal. 2017. V. 22, № 1, pp. 616-624.

15. K. Frankie, B.A. Wong, A. Saleigh et al. Use of Resorbable Fixation System in Pediatric Facial Fractures. J. Craniofac. Surg. 2017. V. 28, № 3, pp. 635-637. 


\section{ДАННЫЕ ОБ АВТОРАХ}

Радкевич Андрей Анатольевич, доктор медицинских наук

Научно-исследовательский институт медицинских проблем Севера ФИЦ КНЦ СО РАН

ул. Партизана Железняка, 32, г. Красноярск, 660022, Российская Федерачия

radkevich.andrey@yandex.ru

Гюнтер Виктор Эдуардович, доктор технических наук, профессор Научно-исследовательский институт медицинских материалов и имплантатов с памятью формы ТГУ

ул. 19 Гвардейской дивизии, 17, г. Томск, 634034, Российская Федерация

gunther_47@mail.ru

\section{Синюк Илья Васильевич, аспирант}

Научно-исследовательский институт медичинских проблем Севера ФИЦ КНЦ СО РАН

ул. Партизана Железняка, 32, г. Красноярск, 660022, Российская Федераичия

sinyukiv@gmail.com

Левенец Анатолий Александрович, доктор медицинских наук, профессор

Красноярский государственный медицинский университет им. проф. В.Ф. Войно-Ясенецкого

ул. Партизана Железняка, 1, г. Красноярск, 660022, Российская Федерачия

aalevenets@mail.ru

Стынкэ Георгий Михайлович, ассистент кафедрой хирургической стоматологии и челюстно-лицевой хирургии Красноярский государственный медицинский университет им. проф. В.Ф. Войно-Ясенецкого

ул. Партизана Железняка, 1, г. Красноярск, 660022, Российская Федерачия

stynkegosha@gmail.com 
Мамедов Расим Халигович, аспирант

Научно-исследовательский институт медицинских проблем Севера ФИЦ КНЦ СО РАН

ул. Партизана Железняка, 32, г. Красноярск, 660022, Российская Федерация

don.ras2012@mail.ru

Подгорный Василий Юрьевич, аспирант

Научно-исследовательский институт медицинских проблем Севера ФИЦ КНЦ СО РАН

ул. Партизана Железняка, 32, г. Красноярск, 660022, Российская Федераиия

impn@impn.ru

Гантимуров Александр Алексеевич, кандидат медицинских наук, главный врач

Городская стоматологическая поликлиника №8

ул. Мирошниченко, 1, г. Красноярск, 660119, Российская Федерация

Журавлева Татьяна Борисовна, кандидат медицинских наук, ассистент кафедры стоматологии детского возраста

Красноярский государственный медииинский университет им. проф. В.Ф. Войно-Ясенецикого

ул. Партизана Железняка, 1, г. Красноярск, 660022, Российская Федерачия

kostyazhuravlev1964@mail.ru

\section{DATA ABOUT THE AUTHORS}

\section{Radkevich Andrey Anatolevich, MD}

Scientific Research Institute of Medical Problems of the North 3g, Partizan Zheleznyak Str., Krasnoyarsk, 660022, Russian Federation radkevich.andrey@yandex.ru

Gyunter Viktor Eduardovich, Doctor of Technical Sciences, Professor Research Institute of Medical Materials and Implants with Form Memory, Tomsk State University

17, 19 Guards Division Str., Tomsk, 634034, Russian Federation gunther_47@mail.ru 
Sinyuk Ilya Vasilevich, Graduate Student

Scientific Research Institute of Medical Problems of the North

3g, Partizan Zheleznyak Str., Krasnoyarsk, 660022, Russian Federation

sinyukiv@gmail.com

Levenets Anatoliy Aleksandrovich, MD, Professor

Krasnoyarsk State Medical University

1, Partizan Zheleznyak Str., Krasnoyarsk, 660022, Russian Federation

aalevenets@mail.ru

Stynke Georgiy Mikhaylovich, Assistant of the Department of Surgical Dentistry and Maxillofacial Surgery

Krasnoyarsk State Medical University

1, Partizan Zheleznyak Str., Krasnoyarsk, 660022, Russian Federation stynkegosha@gmail.com

Mamedov Rasim Khaligovich, Graduate Student

Scientific Research Institute of Medical Problems of the North

3g, Partizan Zheleznyak Str., Krasnoyarsk, 660022, Russian Federation don.ras2012@mail.ru

Podgorny Vasily Yuryevich, Graduate Student

Scientific Research Institute of Medical Problems of the North

3g, Partizan Zheleznyak Str., Krasnoyarsk, 660022, Russian Federation impn@impn.ru

Gantimurov Alexander Alekseevich, Candidate of Medical Sciences, Chief Doctor

City Dental Clinic №8

1, Miroshnichenko Str., Krasnoyarsk, 660119, Russian Federation

Zhuravleva Tatyana Borisovna, Candidate of Medical Sciences, Assistant of the Department of Pediatric Dentistry Krasnoyarsk State Medical University

1, Partizan Zheleznyak Str., Krasnoyarsk, 660022, Russian Federation kostyazhuravlev1964@mail.ru 